\title{
Designing of Kurtis with adapted sculpture of city palace, Udaipur
}

\author{
Falguni Choubisa and Rupal Babel
}

Received: 20.07.2020; Revised: 21.10.2020; Accepted: 07.11.2020

See end of the paper for authors' affiliations Rupal Babel

Department of Textiles and Apparel Designing, College of Community and Applied

Sciences, Maharana Pratap

Univesity of Agricultural

Sciences, Udaipur (Rajasthan)

India

Email : babelrupal66@gmail.com
ABSTRACT : Indian culture and its rich heritage of tradition are reflected in many of the various region of this country and Rajasthan is famous for its profile art treasures. The present study explores the possibility of designing of kurtis with adapted sculpture of city palace, Udaipur. The objective of present study was to develop value added Kurtis using motifs through stencil printing. Researcher used previously adapted sculpture of city palace for kurti design and developed ten placements for Kurtis design by using coral draw software and get it evaluated by experts. To find to five placements researcher used frequency percentage and mean per cent score was calculated to analyze the data. 10 motifs were selected for placement designs, 10 placements were developed by using previously selected and adapted motifs and top 5 placements were selected for development of Kurtis designs. Developed designs were innovative and efforts of the researcher was appreciated and all the designs were cost and effective and new style for wearers.

KEY WORDS: Designing, Kurti, Adaptation

- HOW TO CITE THIS PAPER : Choubisa, Falguni and Babel, Rupal (2020). Designing of Kurtis with adapted sculpture of city palace, Udaipur. Asian J. Home Sci., 15 (2) : 260-263, DOI: 10.15740/HAS/ AJHS/15.2/260-263. Copyright@ 2020: Hind Agri-Horticultural Society. 